Article

\title{
Theoretical and Experimental Studies of a Digital Flow Booster Operating at High Pressures and Flow Rates
}

\author{
Chenggang Yuan, Vinrea Lim Mao Lung, Andrew Plummer and Min Pan * \\ Centre for Power Transmission and Motion Control, Department of Mechanical Engineering, University of Bath, \\ Claverton Down BA2 7AY, UK; cy466@bath.ac.uk (C.Y.); vlml20@bath.ac.uk (V.L.M.L.); arp23@bath.ac.uk (A.P.) \\ * Correspondence: m.pan@bath.ac.uk
}

Received: 18 December 2019; Accepted: 4 February 2020; Published: 10 February 2020

check for updates

\begin{abstract}
The switched inertance hydraulic converter (SIHC) is a new technology providing an alternative to conventional proportional or servo-valve-controlled systems in the area of fluid power. SIHCs can adjust or control flow and pressure by means of using digital control signals that do not rely on throttling the flow and dissipation of power, and provide hydraulic systems with high-energy efficiency, flexible control, and insensitivity to contamination. In this article, the analytical models of an SIHC in a three-port flow-booster configuration were used and validated at high operating pressure, with the low- and high-pressure supplies of 30 and 90 bar and a high delivery flow rate of $21 \mathrm{~L} / \mathrm{min}$. The system dynamics, flow responses, and power consumption were investigated and theoretically and experimentally validated. Results were compared to previous results achieved using low operating pressures, where low- and high-pressure supplies were 20 and 30 bar, and the delivery flow rate was $7 \mathrm{~L} / \mathrm{min}$. We concluded that the analytical models could effectively predict SIHC performance, and higher operating pressures and flow rates could result in system uncertainties that need to be understood well. As high operating pressure or flow rate is a common requirement in hydraulic systems, this constitutes an important contribution to the development of newly switched inertance hydraulic converters and the improvement of fluid-power energy efficiency.
\end{abstract}

Keywords: digital hydraulics; switched inertance hydraulic systems; high-speed switching valves; pressure booster; flow booster; efficient fluid power

\section{Introduction}

Digital hydraulics is a new technology providing an alternative to conventional proportional or servo-valve-controlled systems in the area of fluid power. It promises hydraulic systems with high-energy efficiency, flexible control, and insensitivity to contamination [1-5]. The switched inertance hydraulic converter (SIHC) concept is a subdomain of digital hydraulics [5-7], which is analogous to the electrical buck converter. It makes use of the inherent reactive behaviour of hydraulic components, including high-speed switching valves (switch function), small diameter tubes (inductive effect), and accumulators (capacitive effect) acting as a switch, an inductor, and a capacitor in the electrical circuit. Figure 1 shows a schematic of a three-port flow booster, which is a typical configuration of SIHCs [8-11]. The three-/two-way high-speed switching valve alternatively switches between the high- and low-pressure supply port. When the high-speed valve connects to the supply pump, the high-velocity fluid passes from pump to load; when the valve switches from the pump to the low-pressure supply port, the momentum of the fluid in the inertance tube draws the continuous flow from the low-pressure supply port to the load despite the adverse pressure gradient. As long as the switching time of the valve is short, the reduction in delivery flow is very small, and the average delivery flow is boosted and could be significantly higher than the supply flow. 


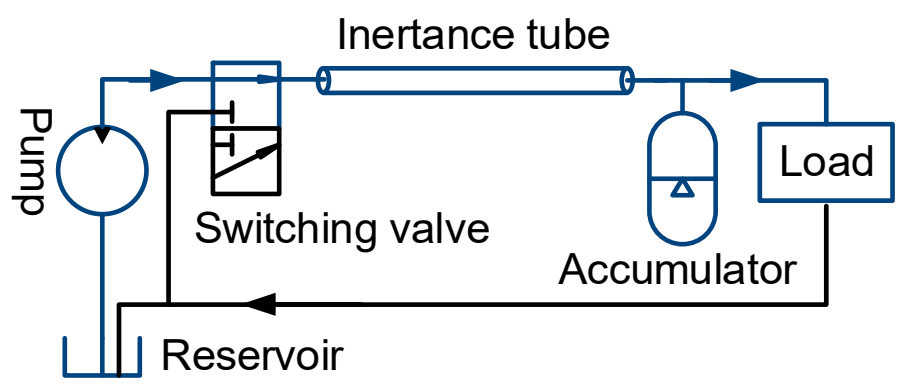

Figure 1. Schematic of three-port flow booster.

The concept of SIHCs was initially proposed by Brown et al. in 1987 [12]. The team proposed and investigated a series of SIHC configurations, including a step-down transformer (flow booster), step-up transformer (pressure booster), switching gyrator, and four-port SIHC analogously to electrically switch inductance transformers. They concluded that hydraulic transformers have clear potential to improve hydraulic-system bandwidth and energy efficiency on the basis of comprehensive theoretical and experimental studies [12-14]. However, due to the limitations of manufacturing high-speed switching valve in the 1980s, continuous work was limited. In the past decade, SIHC research came from Linz (Austria), the United States, Canada, the Nordic countries, Brazil, and Bath (UK).

This research can be categorised as SIHC characteristics, SIHC optimisation, and high-speed switching-valve design. Scheidl et al. designed a resonator, and found that a high-speed valve with a switching frequency of $1 \mathrm{kHz}$ is required for a resonator with a length of $0.65 \mathrm{~m}$ [15]. They proved Brown's conclusion that the performance of a high-speed switching valve is a limiting factor in the development of SIHCs. To tackle this challenge, in 2006, Winkler and Scheidl designed a high-speed solenoid-controlled spool valve with a nominal flow rate of $45 \mathrm{~L} / \mathrm{min}$ at a pressure drop of 5 bar. The valve had a fast response speed of $1 \mathrm{~ms}$ [16]. Winkler also designed an alternative poppet valve with a higher delivery flow rate of $90 \mathrm{~L} / \mathrm{min}$ and a similar pressure drop of 5 bar [17]. However, this valve had a slower response speed of $2 \mathrm{~ms}$. The first hydraulic switching converter was built by the team in Lehigh University [13]. Later, Kogler, and Scheidl reviewed two typical hydraulic switching converters (HBC) and concluded that the performance of hydraulic converters was affected by valve dynamics, parasitic effects, wave propagation along the pipe, system nonlinearities, and pressure pulsations [8]. The HBC was compactly designed [18], and then applied to control the leg of a quadruped robot $[19,20]$ and caster-mould resonant drives [21].

In Bath in 2009, Johnston carried out theoretical and experimental work on the switched inertance device for the efficient control of pressure and flow [22]. He developed simulation models of a flow booster and a pressure booster in a three-port valve configuration. The experimental work was performed using a rotary valve that could only be used for very short periods due to extreme noise and vibration. Maximal experimental delivery pressure was 100 bar, and delivery flow rate was about $15 \mathrm{~L} / \mathrm{min}$.

In 2014, Pan et al. developed ideal analytical distributed models of a three-port SIHC that further enhanced the models, including switching-valve transition dynamics, nonlinearity, and leakage [11]. They validated the models in experiments using a commercial proportional directional valve from Parker Hannifin (DFplus), a high-speed linear valve, and a high-speed rotary valve. Experiment results proved the effectiveness of the analytical models. However, operating pressure and flow were low, with a maximal pressure of 60 bar and a delivery flow rate of $12 \mathrm{~L} / \mathrm{min}$. Pan et al. also developed analytical models of a four-port SIHC in which two inertance tubes were used.

Unlike the one-direction control of a three-port configuration, the four-port SIHC provides real four-quadrant operation and seamless directional changes [23]. The model was validated in experiments with an operating pressure of 32 bar and very small flow rates. Wu et al. developed a rotary hydraulic converter for variable load [24]. A new rotary module is designed as an inertia element for converter energy improvement. Simulated results showed good performance of the designed 
system. The simulated high and low pressures are 50 bar and 10 bar, and the experimental validation is needed [24].

Little work has been done to investigate the performance of SIHCs when they operate at high pressures and flow rates, both theoretically and experimentally. To bridge this gap, this article investigates the performance of a three-port flow booster with a high-speed rotary valve that operates at high pressure of 90 bar and flow rate of $21 \mathrm{~L} / \mathrm{min}$. It contributes to the digital hydraulics area by validating the high efficiency of SIHCs operating at high pressures and flow rates. The enhanced analytical model of the flow booster is briefly reviewed in Section 2, and used to analyse the experimental results in Section 3. The relationship between delivery pressure, switching ratio and frequency, and flow loss is discussed, followed by an investigation of system energy efficiency and power loss. The discussion and conclusions are presented in Section 4.

\section{Previous Studies: Analytical Models and Experiment Investigations}

The distributed analytical model of an ideal three-port SIHC was proposed in [10], and the enhanced model, including switching-valve transition dynamics, nonlinearity, and leakage was proposed in [11]. The analytical models were based on the mixed time-domain and frequency-domain approach in which linear parts (initial pressures, flow, and system impedance) are modeled in the frequency domain, while nonlinear and time-dependent parts (leakage, valve transition dynamics, and system nonlinearity) are modeled in the time domain; an iterative technique is used to link them. The models can effectively predict SIHC physical characteristics and provide a tool to aid in SIHC design.

A brief introduction is given here for the enhanced three-port SIHC analytical models that are used for further analysis in this paper. A detailed derivation can be found in [11]. A typical flow booster is shown Figure 2, where $p_{\mathrm{H}}$ is the high-pressure supply, $p_{\mathrm{L}}$ is the low-pressure supply, and $p_{\mathrm{d}}$ is the delivery pressure. Two pressure sources $p_{1}$ and $p_{2}$, were used to represent the open and closed ports of the three-port high-speed switching valve. $P_{3}$ is the inlet pressure of the inertance tube. $R_{\operatorname{tr}}$ is switching transition resistance, and $R_{\mathrm{u}}$ is the underlap/overlap resistance of the valve. $R_{\text {non1 }}$ and $R_{\text {non2 }}$ represent the nonlinear characteristics of the valve when it connects to the open and closed ports. $Q_{1}$ and $q_{2}$ are the flow rates from the open and closed ports when $q_{3}$ is the total outlet flow from valve to inertance tube. Tube resistance is $R_{\text {tube }}$ and tube inertance is $I_{\text {tube }}$.

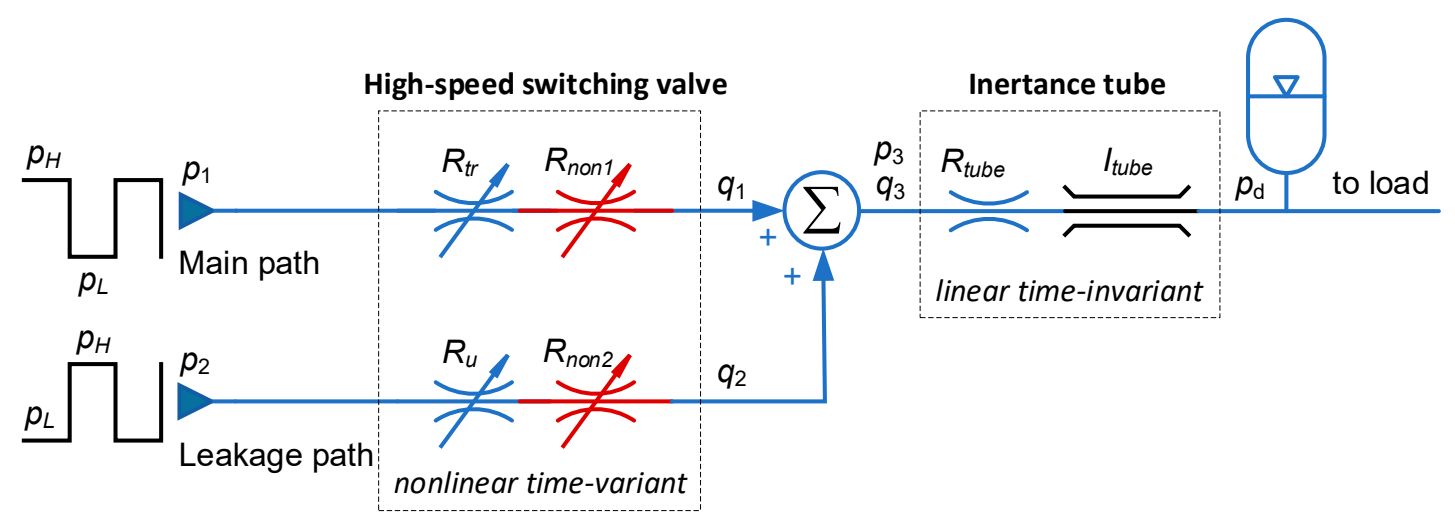

Figure 2. Schematic of enhanced analytical model of a three-port flow booster [11].

Assuming $P_{1}$ is the Fourier transform of $p_{1}$, the system flow of $q_{3}$ can be represented in the time domain as:

$$
q_{3}=\operatorname{IFFT}\left(\frac{P_{1}}{Z_{E}}\right)
$$

where $Z_{E}$ is entry impedance, which is the ratio of the pressure and flow of the entry to the circuit, and the entry impedance of $Z_{E}$ in the frequency domain is 


$$
Z_{E}=j Z_{0} \xi \tan \left(\frac{\omega L \xi}{c}\right),
$$

where $j$ is the imaginary unit, $Z_{0}$ is the pipe characteristic impedance, $c$ is the speed of sound and $\xi$ is the viscous wave correction factor [25].

Therefore, flow from the leakage path and from the main path can be calculated by

$$
\begin{gathered}
q_{2}=C_{d} A_{\text {leak }} \sqrt{\frac{2\left|p_{2}-p_{3}\right|}{\rho}} \operatorname{sgn}\left(p_{2}-p_{3}\right), \\
q_{1}=q_{3}-q_{2}
\end{gathered}
$$

where $c_{d}$ is discharge coefficient, $A_{\text {leak }}$ is leakage area, and $\rho$ is fluid density.

Iterative pressures are dependent on nonlinear time-variant parts

$$
\begin{gathered}
p_{1(k+1)}^{\prime}=\lambda\left(p_{1}-\frac{\rho q_{1(k)}\left|q_{1(k)}\right|}{2 C_{d}^{2} A^{2}}\right)+p_{1(k)}^{\prime}(1-\lambda) \\
p_{2(k+1)}^{\prime}=p_{2}-p_{1(k+1)^{\prime}}^{\prime}
\end{gathered}
$$

where $A$ is the opening area of the valve, $\lambda$ is the relaxation factor for model stability, and $k$ is the index of iteration.

SIHC characteristics can be effectively predicted using Equations (1)-(6). The volume effects from the tube, valve chamber, and accumulators can also be included in the analytical model, as developed in [11]. Investigations of the nonlinearity of valve dynamics, switching-valve transition, leakage, and the accumulator-volume effect are fundamental in SIHC research.

Optimal switching frequencies and ratios are highly dependent on the wave-propagation effect. In our previous work [11], we concluded that the optimal switching frequency can be predicated using Equation (7):

$$
f= \begin{cases}\frac{\alpha c}{2 L} & 0 \leq \alpha \leq 0.5 \\ \frac{(1-\alpha) c}{2 L} & 0.5<\alpha \leq 1\end{cases}
$$

where $f$ is the switching frequency, $\alpha$ is the switching ratio, $L$ is the length of the inertance tube, and $c$ is the speed of sound.

Recent experiment investigations based on a high-speed rotary valve and low operating pressure can be found in [1]. High pressure was set at 30 bar and low pressure at 20 bar, with a delivery flow of 7 and $20 \mathrm{~L} / \mathrm{min}$. The estimated overall resistance was about $0.36 \mathrm{bar} /(\mathrm{L} / \mathrm{min})$. The static delivery pressures agreed well with the analytical results, but a small right-hand-side shift was noticed in the experiment flow-loss curves. Theoretically, a symmetrical flow-loss curve is expected with a switching ratio from 0 to 1 . High flow losses occurred with the predicated/calculated optimal switching frequencies and ratios when a large delivery-flow rate was applied, for example, $20 \mathrm{~L} / \mathrm{min}$, which were not expected according to theoretical analysis.

\section{Flow Booster Operating at High Pressures and Flow Rates}

The schematic of the test rig is shown in Figure 3, consisting of a high-speed rotary valve, an inertance tube, and a needle valve acting as load. The design and steady-state characteristics of the high-speed rotary valve can be found in [1]. A brushless servomotor (Baldor BSM50N-375AF) with a maximal speed of $5100 \mathrm{rpm}$ was used to drive the high-speed switching valve with certain switching frequencies. The switching ratio of the valve was manually adjusted in experiments. 


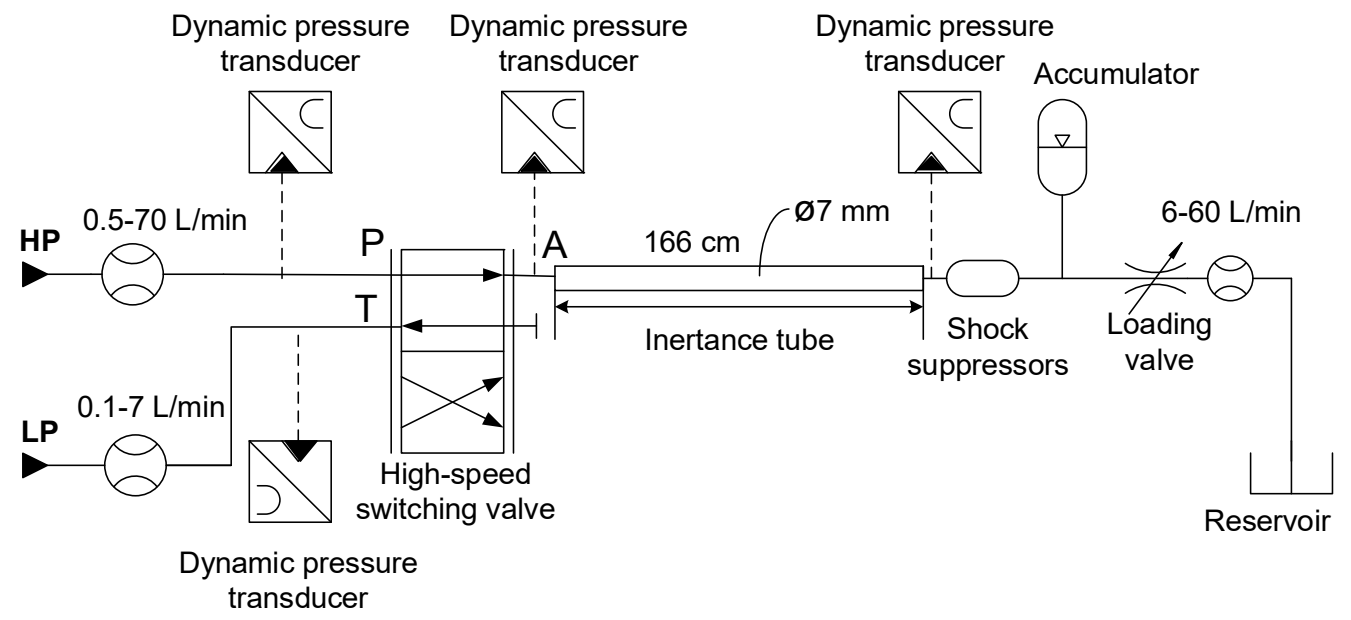

(a)

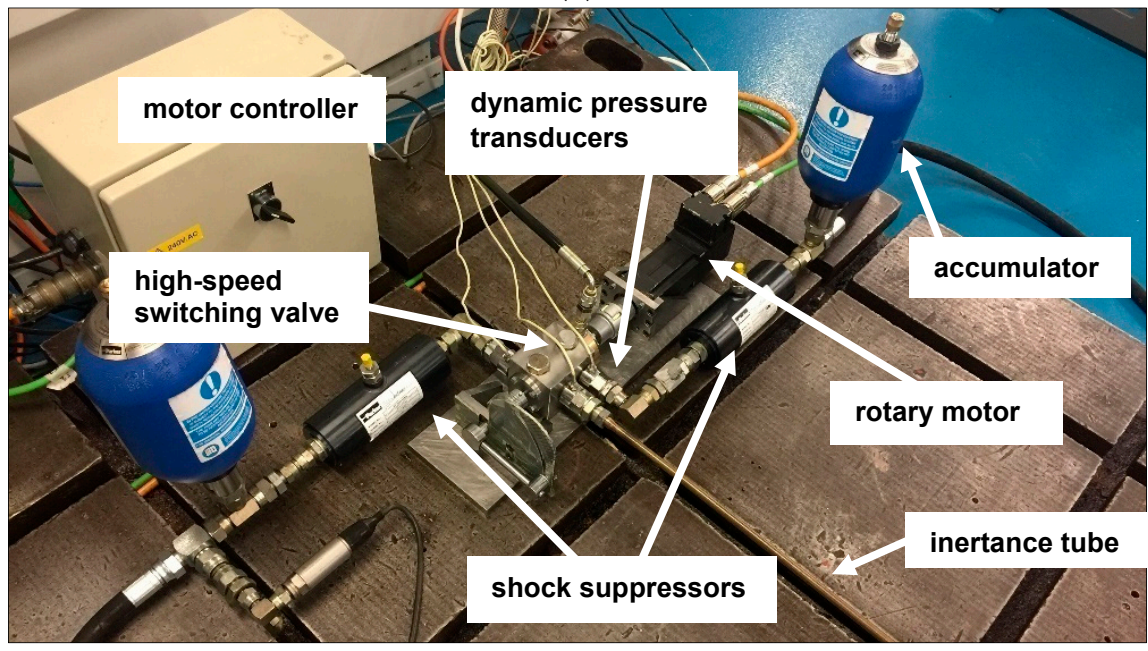

(b)

Figure 3. Test-rig (a) schematic and (b) photograph.

Four miniature piezoresistive pressure transducers (Measurement Specialties EPXseries) were used to measure high- and low-supply pressures, the inlet pressure of the inertance tube (A-port pressure), and the inlet pressure of the needle valve (loading pressure). Transducer ranges were 0-350, 0-35, 0-200, and 0-200 bar, respectively. A hydraulic power pack, including two gear pumps with a maximal supply pressure of 100 and 50 bar, was used as high and low-pressure supply, respectively. Three accumulators and three shock suppressors (Inline Pulse-Tone ${ }^{\mathrm{TM}}$ Shock Suppressors, Parker Hannifin, Ohio, United States) were used to eliminate pressure pulsations. The charging pressures of the high-pressure (HP), low-pressure (LP), and downstream accumulators were 30, 15, and 30 bar, and the charging pressures of the shock suppressors were $15,7.5$, and 15 bar, respectively. The length of the inertance tube was $1.66 \mathrm{~m}$ with a diameter of $7 \mathrm{~mm}$. Two gear flow meters $(0.5-70$ and $0.1-7 \mathrm{~L} / \mathrm{min})$ were used to measure the dynamic high- and low-supply flow rates. Delivery flow rate was measured by using a turbine flow meter $(6-60 \mathrm{~L} / \mathrm{min})$. The estimated speed of sound was $1300 \mathrm{~m} / \mathrm{s}$. More details about the measurement and effect of the speed of sound can be found in [26]. Parameters for the analytical model and experiments are listed in Table 1. 
Table 1. Parameters for analytical model and experiments.

\begin{tabular}{cc}
\hline Parameters & Value (Unit) \\
\hline Fluid viscosity & $30 \mathrm{cSt}$ \\
Fluid density & $870 \mathrm{~kg} / \mathrm{m}^{3}$ \\
High-supply pressure & $90 \mathrm{bar}$ \\
Low-supply pressure & $30 \mathrm{bar}$ \\
Delivery-flow rate & $0,14,21 \mathrm{~L} / \mathrm{min}$ \\
Switching frequency & $200 \mathrm{~Hz}$ \\
Switching ratio & $0-1$ \\
Inertance tube length & $1.66 \mathrm{~m}$ (including fittings) \\
Inertance tube diameter & $7 \mathrm{~mm}$ \\
Speed of sound & $1300 \mathrm{~m} / \mathrm{s}$ \\
Oil temperature & $30^{\circ} \mathrm{C}$ \\
\hline
\end{tabular}

\subsection{Delivery Pressure and System-Flow Loss}

To investigate the performance of the flow booster operating at high pressures, high- and low-supply pressures were set as 90 and $30 \mathrm{bar}$, with a delivery-flow rate of 0,14 , and $21 \mathrm{~L} / \mathrm{min}$. The pressure difference between the two supplies was 60 bar. Switching frequency was $200 \mathrm{~Hz}$, and the switching ratio increased from 0 to 1 . The relationship between delivery pressure, supply pressures, and delivery-flow rate was investigated through experiments, as shown in Figure 4. Theoretically, the delivery pressure should have a linear relationship with supply pressures $p_{H}$ and $p_{L}$, and overall system resistance $R$, as shown in Equation (8):

$$
p_{d}=p_{H} \alpha+(1-\alpha) p_{L}-q_{d} R
$$

where $\alpha$ is switching ratio, $q_{d}$ is delivery flow, and $R$ is overall resistance.

Using Equation (8), it could be calculated that the overall resistance of testing system $R$ was about $0.87 \mathrm{bar} /(\mathrm{L} / \mathrm{min})$, which was about 2.4 times the measurement in [1]. As a similar valve and inertance tube were used for the experiments, the high resistance may have been caused by the effects of high-pressure difference between the two pressure-supply lines and the switching transition of the valve. Linear experimental delivery pressure was achieved with a small deviation around the switching ratio of 0.1 , which could be caused by insufficient inertia, leakage, or cavitation at such a low switching ratio for a high delivery-flow and supply-pressure difference. The largest deviation occurred at $21 \mathrm{~L} / \mathrm{min}$, and the smallest at $0 \mathrm{~L} / \mathrm{min}$.

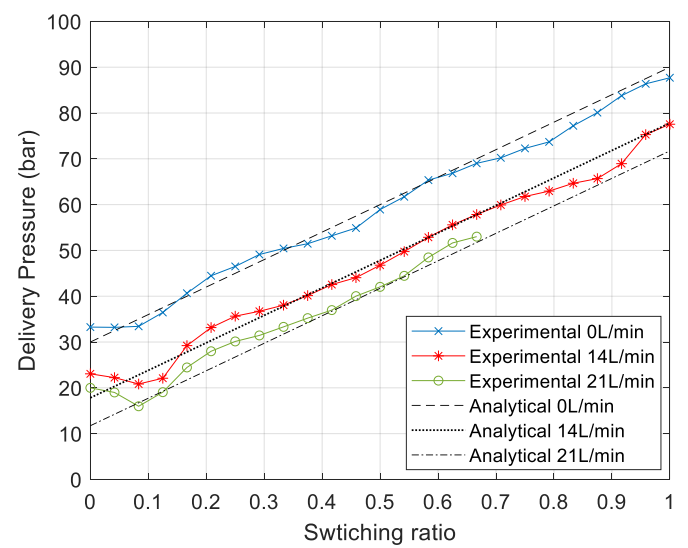

Figure 4. Experiment and analytical delivery pressure (delivery flow $=0,14$, and $21 \mathrm{~L} / \mathrm{min}$; switching frequency $=200 \mathrm{~Hz}$; switching ratio from 0 to 1 ; overall resistance $=0.87 \mathrm{bar} /(\mathrm{L} / \mathrm{min})$ ).

In practice, a reasonable operating range of the switching ratio could be between 0.2 and 0.8 . Due to the capacity of the dual-pump supply, system pressure drops and unavoidable flow drops through 
the relief valves (accompanied by the supply pumps). The system was unable to achieve $21 \mathrm{~L} / \mathrm{min}$ when the switching ratio was greater than 0.6 . However, with a delivery flow rate of $21 \mathrm{~L} / \mathrm{min}$, linearly increasing delivery pressure could be predicted.

The theoretical relationship between flow loss and switching ratio varies with switching frequencies. Unlike the delivery-pressure curve, flow loss is dependent on switching frequency; details can be found in [11]. Flow loss is defined as the difference between actual and theoretical average flow rate from the high- and low-pressure supply ports [10]. Static leakage tests were performed at switching ratios of $0,0.25,0.5$, and 1 . High-pressure supply was 20 bar, and low-pressure supply was 3 bar. In the experiments, when the inertance tube was fully connected to the high-pressure port (switching ratio $=1$ ), leakage flow of $0.57 \mathrm{~L} / \mathrm{min}$ was measured from the high-pressure port to the low-pressure port and the leakage port of the valve. When the inertance tube was fully connected to the low-pressure supply port, a leakage flow of $0.50 \mathrm{~L} / \mathrm{min}$ was measured from the low-pressure supply port to the leakage port. Figure 5 shows the experiment and analytical flow losses with delivery flow rates of 0,14 , and $21 \mathrm{~L} / \mathrm{min}$. Average flow losses were accurately predicted, but differences were seen between experiment and analytical flow losses, which was not predicted. The result was caused by the disturbance wave of the frequency of $134 \mathrm{~Hz}$, which significantly influenced wave propagation along the pipeline and system performance. The harmonics of $134 \mathrm{~Hz}$ can be clearly seen in FFT (Fast Fourier transform) analysis. The $134 \mathrm{~Hz}$ wave, which was 2/3 of the switching frequency of the valve, could have been caused by rig vibrations. This experiment phenomenon has not been analytically explained. The reasons for the generation of the disturbance wave should be investigated. Figure $5 b$ shows the analytical flow losses with a switching frequency of 134 and $200 \mathrm{~Hz}$. Estimated leakage was $2.25 \mathrm{~L} / \mathrm{min}$ with an operating pressure of 90 bar. The curve of $134 \mathrm{~Hz}$ agreed with the experiment flow losses. Experiment results also proved that flow loss is not directly affected by delivery-flow rate [10].

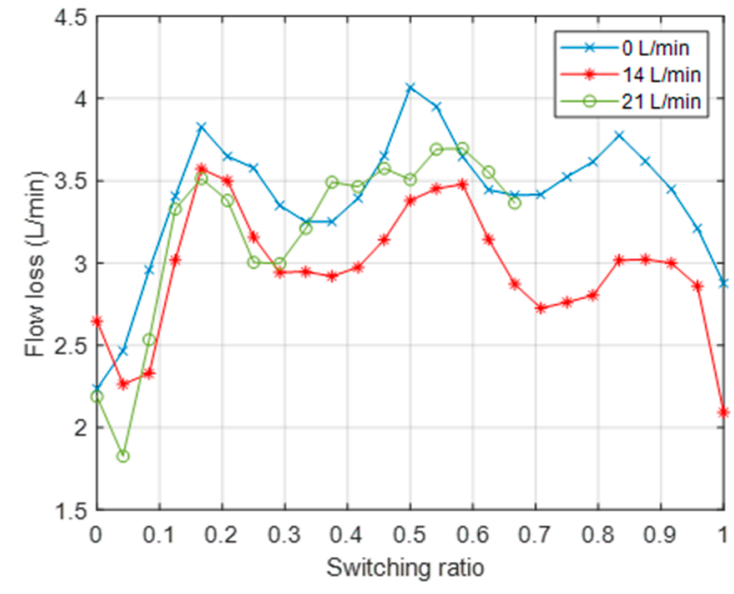

(a)

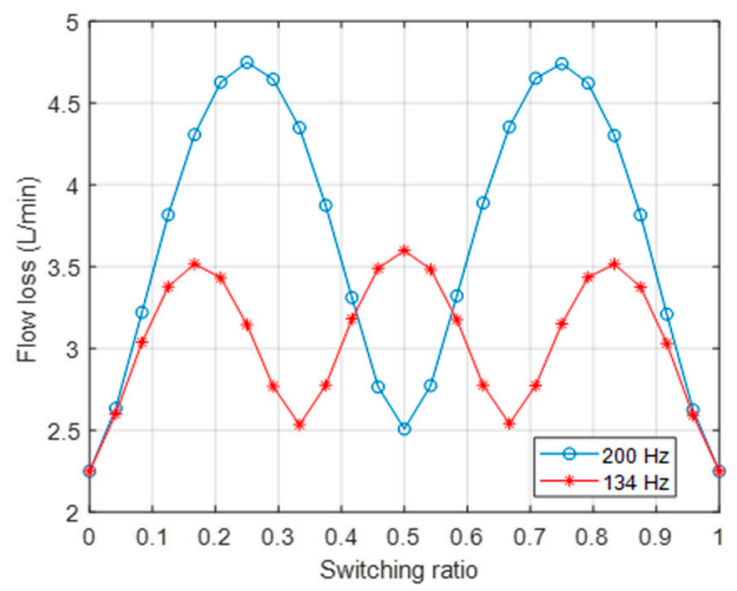

(b)

Figure 5. (a) Experiment flow losses with delivery-flow rate of 0,14 , and $21 \mathrm{~L} / \mathrm{min}$, and switching frequency of $200 \mathrm{~Hz} . /$ (b) Analytical estimations with switching frequency of 200 and $134 \mathrm{~Hz}$.

\subsection{System Efficiency and Power Loss}

Analytical characteristics of the flow booster using the enhanced analytical model and experiment results [11] are shown in Figure 6 for different switching ratios $(0.25,0.5$, and 0.67$)$ and a fixed switching frequency of $200 \mathrm{~Hz}$. The solid, dashed, and dotted lines represent the analytical results, while the squares, triangles, and circles represent the experiment results with a constant delivery-flow rate of 0 , 14, and $21 \mathrm{~L} / \mathrm{min}$. Experimental delivery pressure followed the predicted trend well. The experiment high-pressure supply-flow rates were about $3 \mathrm{~L} / \mathrm{min}$ higher than those pf the analytical results due to larger actual flow losses. 


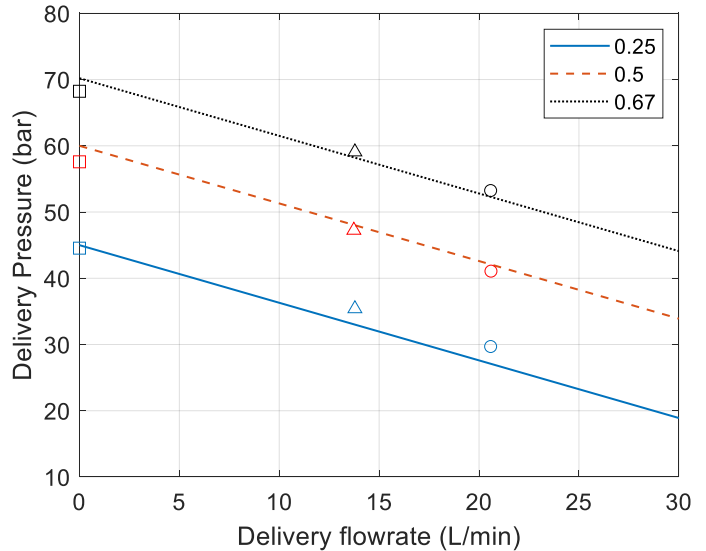

(a)

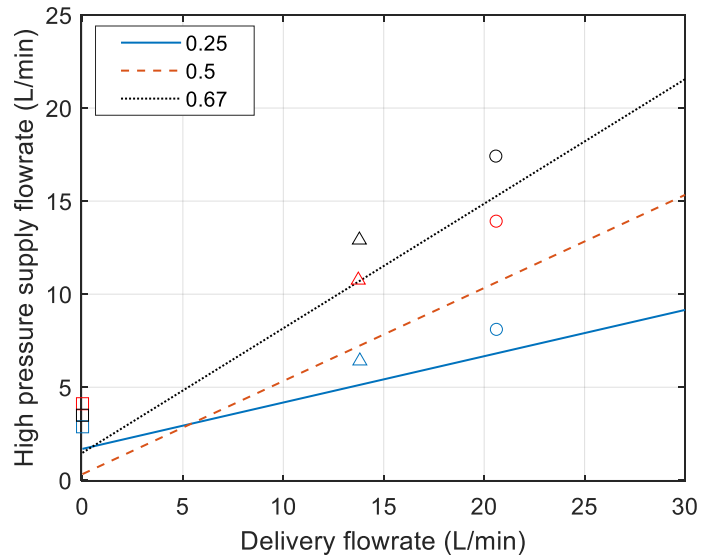

(b)

Figure 6. Experiment and analytical results of flow booster. (a) Delivery pressure versus delivery flow rate; (b) high-pressure supply flow rate versus delivery flow rate.

Figure 7 shows the experimental and analytical efficiency and power losses of a flow booster. The SIHC maintained high efficiency with an average above $65 \%$ with delivery flow rates of 14 and $21 \mathrm{~L} / \mathrm{min}$ for a ratio of $0.25,0.5$, and 0.67 , and a switching frequency of $200 \mathrm{~Hz}$. The solid, dashed, and dotted lines represent the analytical results, while squares, triangles, and circles represent the experiment results with a constant delivery flow rate of 0,14 , and $21 \mathrm{~L} / \mathrm{min}$. Switching-valve transition was observed, and switching time was about $0.8 \mathrm{~ms}$. Compared to a conventional valve-controlled hydraulic machine operating at a pressure of 90 bar and a delivery flow rate of 5, 14, and $21 \mathrm{~L} / \mathrm{min}$, a fixed-displacement pump with a constant flow of $30 \mathrm{~L} / \mathrm{min}$ and a maximal pressure of $150 \mathrm{bar}$ is assumed for use. Conventional system efficiency is $17 \%, 47 \%$, and $70 \%$, corresponding to power loss of 3750, 2400, and $1350 \mathrm{~W}$. The SIHC provides much higher efficiency and lower energy losses with a delivery flow rate from 5 to $21 \mathrm{~L} / \mathrm{min}$. High energy efficiency can only be achieved for a conventional system when it operates around its maximal capacity. Actual efficiency was slightly lower than that in the analytical results, which could have been caused by the simplified prediction of the valve transition dynamics [11], and the neglecting of pressure pulsation (extra pressure harmonics occurred) and cavitation effects.

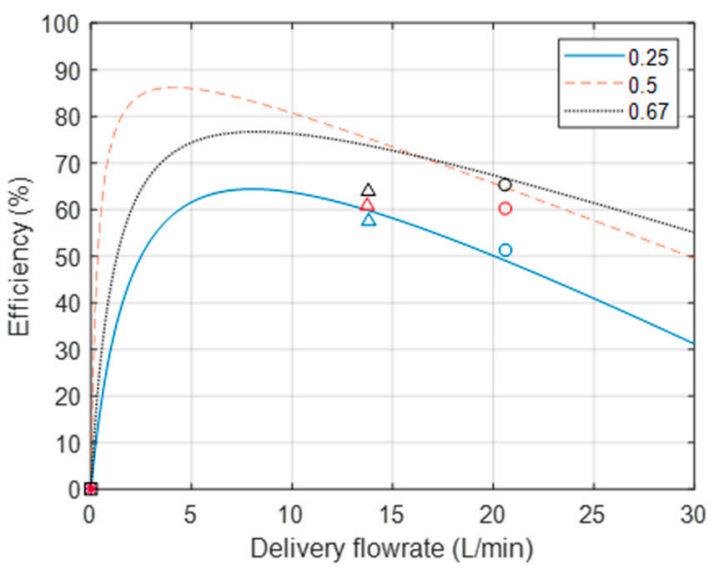

(a)

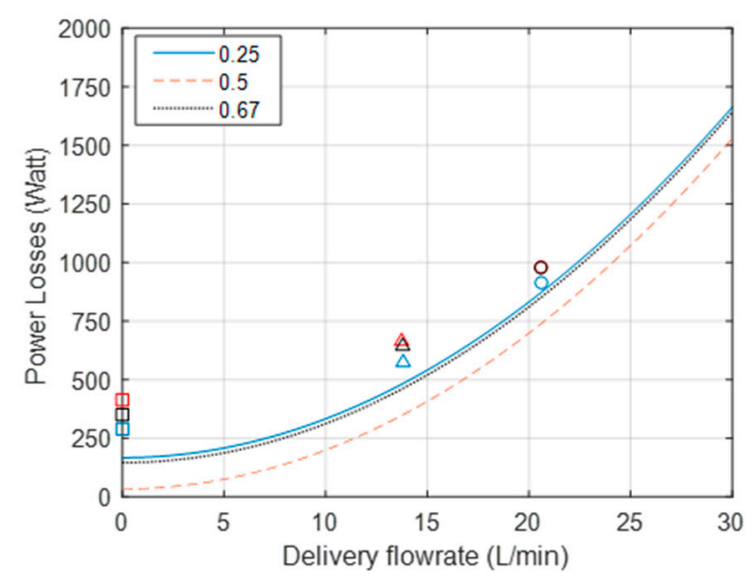

(b)

Figure 7. Experimental and analytical efficiency and power loss of a flow booster. (a) Efficiency versus delivery-flow rate; (b) power loss versus delivery flow rate. 


\section{Discussion and Conclusions}

The main advantage of the SIHC is that the inherent reactive behaviour of a hydraulic tube is used to control flow and pressure, and improve system energy efficiency instead of relying on dissipation of power. High operating pressures with the low- and high-pressure supplies of 30 and 90 bar, and a high delivery flow rate of $21 \mathrm{~L} / \mathrm{min}$ were applied to a flow booster in this work. Results were validated by using the three-port SIHC analytical models. Analytical and experiment results showed very good performance and efficiency for the SIHC when it operated at high pressures and delivery-flow rates, which are normally required for hydraulic applications such as in transportation, aerospace, and machinery for construction, industry, and agriculture. Flow loss and efficiency agreed with the prediction from the analytical model, which directly provided time-efficient solutions without running simulation models that were computationally intensive. Cavitation and vibrations were experienced when low-supply pressure was very low (0-10 bar). In practice, a pressurised tank could be useful for boosting low-supply pressure. Alternatively, a dual-pump system could be used to form two individual supply-pressure lines.

Experiment investigations were based on constant flow rates. We aim to apply a varying flow rate to the system in our continuing work to investigate SIHC adaptability and performance. The loading effect will be investigated and concluded for SIHC design and optimisation. Improving on the current system, a stepper motor will be used to automatically adjust the switching ratio, and a real-time control system will be used to adjust the switching frequency to maintain optimal operating parameters [11,26]. This can further improve system energy efficiency, which is important for a wide range of hydraulic sectors, including machinery for construction, industry, agriculture, transportation, oil and gas, and robotics.

Author Contributions: M.P. and C.Y. developed the analytical models, conceived and designed the experiments, analysed the data, and wrote the paper; V.L.M.L. carried out the experiments and instrumentation work; A.P. gave valuable technical advice and contributed to the manuscript editing. All authors have read and agreed to the published version of the manuscript.

Funding: This research was funded by the RAEng/The Leverhulme Trust Senior Research Fellowship, UK, grant number LTSRF1819 \15 16, the RAEng Proof-of-Concept Award PoC1920/15, and the Open Foundation of the State Key Laboratory of Fluid Power and Mechatronic Systems, Zhejiang University, China, grant number GZKF-201801. Chenggang Yuan would like to thank China Scholarship Council for supporting his PhD (201706150102) while studying at the University of Bath, UK.

Conflicts of Interest: The authors declare no conflict of interest.

\section{References}

1. Scheidl, R.; Linjama, M.; Schmidt, S. Is the future of fluid power digital? Proc. Inst. Mech. Eng. Part I J. Syst. Control Eng. 2012, 226, 721-723. [CrossRef]

2. Yang, H.Y.; Pan, M. Engineering research in fluid power: A review. J. Zhejiang Univ. Sci. A 2015, 16, 427-442. [CrossRef]

3. Pan, M.; Plummer, A. Digital switched hydraulics. Front. Mech. Eng. 2018, 13, 225-231. [CrossRef]

4. Chao, Q.; Zhang, J.; Xu, B.; Huang, H.; Pan, M. A review of high-speed electro-hydrostatic actuator pumps in aerospace applications: Challenges and solutions. J. Mech. Des. 2019, 141. [CrossRef]

5. Yuan, C.; Pan, M.; Plummer, A. A review of switched inertance hydraulic converter technology. In Proceedings of the BATH/ASME 2018 Symposium on Fluid Power and Motion Control, Bath, UK, 12 September 2018.

6. Brandstetter, R.; Deubel, T.; Scheidl, R.; Winkler, B.; Zeman, K. Digital hydraulics and “Industries 4.0”. Proc. Inst. Mech. Eng. Part I J. Syst. Control Eng. 2017, 231, 82-93. [CrossRef]

7. Yuan, C.; Pan, M.; Plummer, A. A review of switched inertance hydraulic converter technology. ASME J. Dyn. Sys. Meas. Control 2020, 1-13. [CrossRef]

8. Kogler, H.; Scheidl, R. Two basic concepts of hydraulic switching converters. In Proceedings of the First Workshop on Digital Fluid Power, Tampere University of Technology, Tampere, Finland, 3 October 2008; Volume 3, pp. 7-30. 
9. Winkler, B. Recent advances in digital hydraulic components and applications. In Proceedings of the Ninth Workshop on Digital Fluid Power, Aalborg, Denmark, 7-8 September 2017.

10. Pan, M.; Johnston, N.; Plummer, A.; Kudzma, S.; Hillis, A. Theoretical and experimental studies of a switched inertance hydraulic system. Proc. Inst. Mech. Eng. Part I J. Syst. Control Eng. 2014, 228, 12-25. [CrossRef]

11. Pan, M.; Johnston, N.; Plummer, A.; Kudzma, S.; Hillis, A. Theoretical and experimental studies of a switched inertance hydraulic system including switching transition dynamics, non-linearity and leakage. Proc. Inst. Mech. Eng. Part I J. Syst. Control. Eng. 2014, 228, 802-815. [CrossRef]

12. Brown, F.T. Switched reactance hydraulics: A new way to control fluid power. In Proceedings of the National Conference on Fluid Power, Chicago, IL, USA, 16-20 October 1987; pp. 25-34.

13. Brown, F.T.; Tentarelli, S.; Ramachandran, S. A hydraulic rotary switched-inertance servo-transformer. J. Dyn. Syst. Meas. Control. 1988, 110, 144-150. [CrossRef]

14. Liaw, C.J.; Brown, F.T. Nonlinear dynamics of an electrohydraulic flapper nozzle valve. J. Dyn. Syst. Meas. Control. 1990, 112, 298-304. [CrossRef]

15. Scheidl, R.; Schindler, D.; Riha, G.; Leitner, W. Basics for the energy-efficient control of hydraulic drives by switching techniques. In Proceedings of the 3rd Conference on Mechatronics and Robotics, Paderborn, Germany, 4-6 October 1995; pp. 118-131.

16. Winkler, B.; Scheidl, R. Optimization of a fast switching valve for big flow rates. In Proceedings of the Bath Workshop on Power Transmission and Motion Control, Bath, UK, 13-15 September 2006; pp. 387-399.

17. Winkler, B.; Scheidl, R. Development of a fast seat type switching valve for big flow rates. In Proceedings of the 10th Scandinavian International Conference on Fluid Power, Tampere, Finland, 21-23 May 2007.

18. Kogler, H.; Scheidl, R.; Ehrentraut, M.; Guglielmino, E.; Semini, C.; Caldwell, D.G. A compact hydraulic switching converter for robotic applications. In Proceedings of the Fluid Power and Motion Control, Bath, UK, 15 September 2010; pp. 55-66.

19. Guglielmino, E.; Semini, C.; Yang, Y.S.; Caldwell, D.; Kogler, H.; Scheidl, R. Energy efficient fluid power in autonomous legged robotics. In Proceedings of the ASME 2009 Dynamic Systems and Control Conference, Hollywood, CA, USA, 12-14 October 2009.

20. Peng, S.; Kogler, H.; Guglielmino, E.; Scheidl, R.; Branson, D.T.; Caldwell, D.G. The use of a hydraulic dc-dc converter in the actuation of a robotic leg. In Proceedings of the 2013 IEEE/RSJ International Conference on Intelligent Robots and Systems, Tokyo, Japan, 3 November 2013; pp. 5859-5864.

21. Kogler, H.; Scheidl, R. Hydraulic switching control of resonant drives. In Proceedings of the 12th Mechatronics Forum Biennial International Conference, Zurich, Switzerland, 28-30 June 2010; pp. 28-30.

22. Johnston, D.N. A switched inertance device for efficient control of pressure and flow. In Proceedings of the ASME 2009 Dynamic Systems and Control Conference, Hollywood, CA, USA, 1 January 2009; pp. 589-596.

23. Pan, M.; Plummer, A.; El Agha, A. Theoretical and experimental studies of a switched inertance hydraulic system in a four-port high-speed switching valve configuration. Energies 2017, 10, 780. [CrossRef]

24. Wu, G.; Yang, J.; Shang, J.; Fang, D. A rotary fluid power converter for improving energy efficiency of hydraulic system with variable load. Energy 2020, 195, 116957. [CrossRef]

25. Stecki, J.S.; Davis, D.C. Fluid transmission lines-Distributed parameter models part 1: A review of the state of the art. Proc. Inst. Mech. Eng. Part A Power Process. Eng. 1986, 200, 215-228. [CrossRef]

26. Pan, M.; Johnston, N.; Robertson, J.; Plummer, A.; Hillis, A.; Yang, H.Y. Experimental investigation of a switched inertance hydraulic system with a high-speed rotary valve. J. Dyn. Syst. Meas. Control. 2015, 137, 121003. [CrossRef]

(C) 2020 by the authors. Licensee MDPI, Basel, Switzerland. This article is an open access article distributed under the terms and conditions of the Creative Commons Attribution (CC BY) license (http://creativecommons.org/licenses/by/4.0/). 